\title{
The effect of cervical mobility on the natural history of cervical spondylotic myelopathy
}

\author{
MP BARNES, M SAUNDERS \\ From the Department of Neurology, Middlesbrough General Hospital, Middlesbrough, UK
}

SUMMARY A retrospective study was made of 45 patients who had been treated conservatively for cervical spondylotic myelopathy. A number of aetiological variables were analysed in an attempt to find factors that may be useful in predicting the long term prognosis for this condition. It was found that those who deteriorated were more likely to be female and to have significantly more cervical mobility when compared to those patients whose disability had remained static. It is proposed that measurement of cervical mobility may help to select patients who are more likely to deteriorate and thus more likely to benefit from surgical intervention.

Compression of the cervical cord is a major factor in the pathogenesis of cervical spondylotic myelopathy.' ' There is variation, however, between the degree of compression and the resulting degree of disability and it seems probable that factors other than simple compression may also play a part. ${ }^{3}$ Adams $^{3}$ and Reid $^{4}$ felt that a high range of cervical mobility may contribute to the pathogenesis and Adams $^{5}$ and others ${ }^{6}{ }^{7}$ further showed that reduction of excessive mobility may be of importance for a successful surgical outcome in this condition. None of the factors implicated in the pathogenesis have been shown to be of definite prognostic value. We have studied 45 patients with cervical spondylotic myelopathy who have been managed conservatively and analysed the group retrospectively to see if any of the aetiological variables could be used to predict the long term outlook for this common condition.

\section{Method}

The case notes were reviewed of all patients who had been seen by the Department of Neurology at Middlesbrough General Hospital during the period 1970-80 with a diagnosis of cervical spondylotic myelopathy. It was found that 76 of these patients had been managed conservatively and an attempt was made to trace this group.

Thirteen patients had died and the cause of death was determined in 10 . In only one case could the death be attributed to cervical spondylotic myelopathy, a woman

Address for reprint requests: Dr MP Barnes, Dept of Neurosurgery, Royal Victoria Infirmary, Queen Victoria Rd, Newcastle upon Tyne, NE1 4LP, UK

Received 12 July 1983. Accepted 6 August 1983 who died aged 87 from bronchopneumonia having been rendered immobile by her myelopathy. Eleven patients could not be traced, six refused to take part and one had emigrated. Thus 45 patients were left for inclusion in the survey.

Each patient was seen by one of us (MPB) and the diagnosis of cervical spondylotic myelopathy was accepted if the patient had: (1) A myelopathy with evidence of corticospinal tract dysfunction in the legs with or without sensory involvement or a radiculopathy, (2) Plain radiological changes of cervical spondylosis. (3) Myelographic evidence of a complete or partial block to the flow of contrast medium in the cervical spine, (4) No other reasonable diagnosis that had manifested itself on follow-up examination.

These criteria were met in all patients except that seven did not have myelography. These people had been considered unfit for surgery and myelography was felt to be unnecessary. They were included in the analysis because follow-up examination failed to reveal any other reasonable diagnosis.

Basic patient details were recorded and each was allotted to one of five grades of current disability according to the disability scale of Nurick' (table 1). A disability grade was also allotted retrospectively according to their disability at the time of initial referral.

Plain lateral radiographs of the cervical spine were taken in full flexion and extension and the following measurements taken:

(1) Minimum sagittal diameter of the cervical canal from $\mathrm{C} 1$ to $\mathrm{C} 7$-measured from the middle of the posterior surface of the vertebral body to the nearest point on the junction of the lamina with the spine. The smallest of these measurements was termed the minimum anteroposterior diameter (Min APD).

(2) Minimum canal size (MCS) - usually the distance from a spur on the vertebral body to the adjacent lamina.

(3) Total amount of subluxation (in $\mathrm{mm}$ ) of one vertebral 
Table 1 Disability grading scale used for current and retrospective grading of functional incapacity (Nurick, 1972)

Grade 1: Signs of spinal cord disease but no difficulty in walking.

Grade 2: Slight difficulty in walking which did not prevent full time employment.

Grade 3: Difficulty in walking which prevented full-time employment or the ability to do all house work, but which was not so severe as to require someone else's help to walk.

Grade 4: Able to walk only with someone else's help or with aid of a frame.

Grade 5: Chairbound or bedridden.

body upon the next in flexion and extension.

(4) Total height (in $\mathrm{mm}$ ) of the posterior osteophytes in the cervical spine-measured as the height of the osteophyte beyond the normal contour of the vertebral body.

(5) Kyphosis and lordosis in flexion and extension (in $\mathrm{mm}$ )-measured as the maximum distance from the posterior curve of the cervical vertebrae to a line joining $\mathrm{C} 7$ to the dens as illustrated in the figure.

(6) Range of neck movement from flexion to extensionsee fig.

(7) Range of head movement-measured by superimposing the axis vertebrae of the flexion and extension films and drawing a line from the uppermost film margin onto the underneath film. The radiographs are: then superimposed over the skull bases and a similar line drawn from the same margin of the upper film onto the lower film. The angle between these two lines

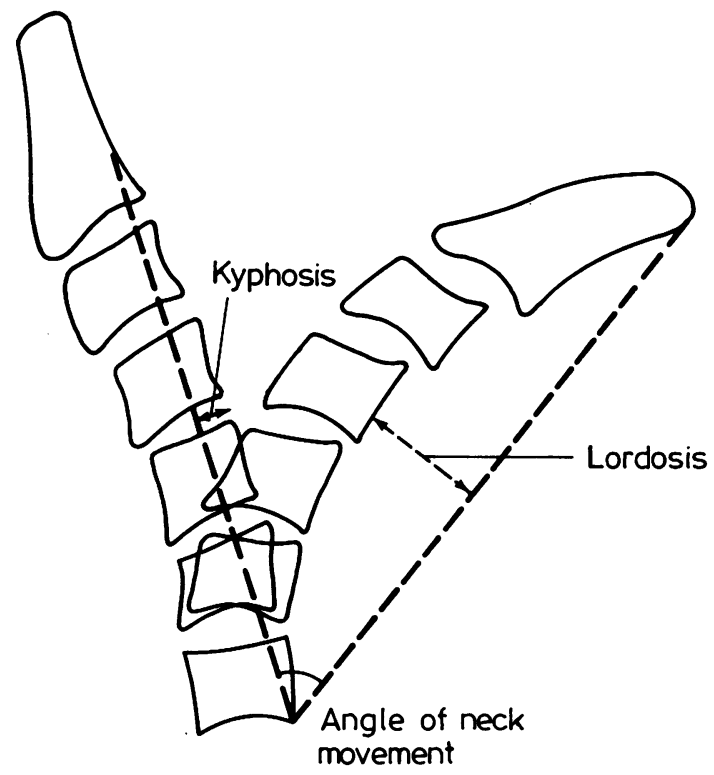

Fig Diagram of lateral cervical radiograph superimposed at C7 to illustrate method of measurement of kyphosis, lordosis and range of neck movement. represents the range of movement of the head upon the neck. (See Adams ${ }^{3}$.)

\section{Results}

Forty-five patients were fully analysed ( 32 men, 13 women) with a mean age of 65 years. The mean follow-up period was 8.2 years and the mean time between symptom onset and first referral was 1.2 years.

The patients were divided into three groups according to the change in their functional disability:

Group 1: Patients who had improved at least one functional grade on follow-up when compared to their grade at initial referral.

Group 2: Patients whose grade was the same at follow-up as at initial referral.

Group 3: Patients who had deteriorated at least one grade at follow-up.

The mean values of the different parameters in these groups can be seen in table 2 .

A number of other clinical factors were analysed to determine whether they had any prognostic value:

(a) Presence of radicular symptoms or signs in the arms (30 patients).

(b) Presence of sensory symptoms or signs in the legs (15 patients).

(c) Presence of sphincter involvement (3 patients).

(d) Onset of symptoms in relation to neck trauma (3 patients).

(e) Nature of employment.

(f) Use of a collar-recommended to 15 patients but only worn regularly by 3 .

None of these factors had any prognostic value. It is of interest to note, however, that all those who deteriorated had both sensory symptoms in the legs and radicular symptoms in the arms.

Statistical analysis of the results shown in table 2 shows no significant differences between Group 1 and Group 2 (Better v. Same). Analysis of Group 2 v.

Table 2 Mean values of different parameters in each patient group

\begin{tabular}{|c|c|c|c|}
\hline & Group 1 & Group 2 & Group 3 \\
\hline $\begin{array}{l}\text { No of patients } \\
\text { Male: female ratio } \\
\text { Mean symptom length (years) } \\
\text { Mean age (years) } \\
\text { Mean min APD (mm) } \\
\text { Mean MCS (mm) } \\
\text { Mean subluxation (mm) } \\
\text { Mean posterior osteophytosis (mm) } \\
\text { Mean neck range (degrees) } \\
\text { Mean head range (degrees) } \\
\text { Mean total range (degrees) } \\
\text { Mean lordosis in extension }(\mathrm{mm}) \\
\text { Mean kyphosis in flexion }(\mathrm{mm})\end{array}$ & $\begin{array}{l}9 \\
9: 0 \\
7 \cdot 8 \\
64 \\
14 \cdot 4 \\
12 \cdot 4 \\
1 \cdot 8 \\
5 \cdot 7 \\
25 \cdot 8 \\
21 \cdot 6 \\
47 \cdot 3 \\
14 \cdot 3 \\
2 \cdot 6\end{array}$ & $\begin{array}{l}30 \\
22: 8 \\
8 \cdot 3 \\
65 \\
14 \cdot 9 \\
12 \cdot 8 \\
2 \cdot 2 \\
5 \cdot 3 \\
30 \cdot 0 \\
18 \cdot 2 \\
48 \cdot 3 \\
14 \cdot 7 \\
3 \cdot 5\end{array}$ & $\begin{array}{l}6 \\
1: 5 \\
8 \cdot 5 \\
67 \\
14 \cdot 8 \\
12 \cdot 8 \\
1 \cdot 3 \\
6 \cdot 5 \\
39 \cdot 7 \\
29 \cdot 0 \\
68 \cdot 0 \\
13 \cdot 8 \\
5 \cdot 7\end{array}$ \\
\hline
\end{tabular}

See Method for explanation of measurements. 
Group 3 (Same v. Worse) shows the following significant factors: (1) There are more women in Group $3(p<0.01)$, (2) The range of neck movement is greater in Group $3(p<0.05)$, (3) The range of head movement is also higher in Group 3 (p $<0.01$ ), (4) The total range of head and neck movement shows a highly significant difference between the two groups $(\mathrm{p}<0.01)$.

\section{Discussion}

A major factor in the pathogenesis of cervical spondylotic myelopathy is a constitutionally narrow cervical canal that is further narrowed by the encroachment of osteophytes.' ' Other mechanisms that may cause additional narrowing of the canal include buckling of the ligamentum flavum during neck extension ${ }^{*}$ and subluxation of one vertebral body upon the next." Other authors feel that involvement of the vasculature of the cord in these compressive processes may further contribute to the pathogenesis." However, there is variation between the degree of cord compression and the severity of the resulting myelopathy.' = In addition, simple surgical decompression of the cord does not always yield satisfactory long term results. ${ }^{5}$ It seems likely, therefore, that factors other than compression may contribute to the aetiology of cervical spondylotic myelopathy. Adams and Logue" 1 felt that movement of the cervical spine and consequent movement of the cord within the canal was also important. Reid had previously shown that the cord not only moved up and down within the canal during flexion and extension but also stretched by about $10 \%$ during full flexion. Both authors felt that this movement of the cervical cord during flexion against the protruding osteophytes was an important factor in the production of cervical spondylotic myelopathy.

If this mechanism is important it would be expected that reduction of spinal mobility would alleviate the recurrent trauma to the cord and improve prognosis. This could be achieved either surgically by vertebral fusion or by external fixation with a collar. Gruningen ${ }^{\circ}$ felt that the success of Cloward's operation was secondary to the immobilisation of the cervical spine. In his series 10 out of 18 patients with a post-operative mobility of less than $30^{\circ}$ of cervical movement improved whereas only two out of eight with movement greater than this did so. Adams $s^{5}$ found the best post-operative results in patients showing a restriction of cervical mobility below $40^{\circ}$ and Gonsalez-Feria' found the best results followed fixation of the cervical spine. The use of a collar is difficult to evaluate as the patient may find it both uncomfortable and socially unacceptable and compliance may therefore be a problem. In this series only three patients admitted to regular use of their collar despite it being recommended to 15 . Balla, Walton and Hankinson'" showed no demonstrable effect on the myelopathy by immobilisation in a Victoria Camp collar. However, Clarke and Robinson $^{13}$ showed that of 16 patients treated by collar alone eight improved and eight were unchanged over a $2 \frac{1}{2}$ year period. Campbell and Phillips ${ }^{14}$ used a Minerva plaster for three months followed by a short plastic collar for a variable period and found that none of their 13 patients deteriorated over $2-5$ years. Perhaps stricter use of a collar may lead to better results.

The natural history of cervical spondylotic myelopathy most commonly shows a pattern of a short period of deterioration followed by a long period of relative stability. ${ }^{15}$ It is generally agreed that the best chance of influencing this course is by early surgical intervention during the initial phase. A number of reports show a better surgical outcome if symptoms have been present less than one year. ${ }^{16} 17$ Roosen ${ }^{16}$ showed that $43 \%$ of his patients improved after operation in these circumstances whereas the figure was only $15 \%$ if the symptoms had been present for more than a year. However, many people do not present to hospital within this time and may be at the beginning of a long period of stability at the time of their first referral. In this series the mean time from symptom onset to referral was $1 \cdot 2$ years. The time for surgical intervention, therefore, may have passed.

In these circumstances it would be useful if a predictive factor were available that could pick out those people who were more likely to get worse and therefore more likely to benefit from surgical intervention. Nurick ${ }^{18}$ found the only such factor to be increasing age but this has not been borne out by other studies nor the present work. This series has indicated that the female sex may be an indicator of poorer prognosis. No study has shown that measurement of the degree of compression is of prognostic value. In this series the minimum AP diameter, minimum canal size, degree of subluxation and amount of posterior osteophytosis all had no predictive value. However, the range of neck and head movement did differentiate between those who had worsened at follow-up and those who had remained static. All patients, with one exception, who had a total range of movement greater than $62^{\circ}$ deteriorated whilst none did so with total movement below this figure.

The series is retrospective and the range of cervical movement on follow-up may not represent the range at initial presentation. However, it can be said that those who retain a substantial range of movement seem more likely to deteriorate. Perhaps those 
patients who present later than one year after the start of their symptoms merit measurement of their neck movement. This may then be a useful pointer to those in whom surgery may be needed to reduce an excessive degree of cervical mobility and to those in whom conservative management would be more appropriate.

\section{References}

' Nurick S. The pathogenesis of the spinal cord disorder associated with cervical spondylosis. Brain 1972;95:87100.

'Payne EE, Spillane JD. The cervical spine. An anatomico-pathological study of 70 specimens (using a special technique) with particular reference to the problem of cervical spondylosis. Brain 1957;80:571-96.

${ }^{3}$ Adams CBT. Logue V. Studies in cervical spondylotic myelopathy. II. The movement and contour of the spine in relation to the neural complications of cervical spondylosis. Brain 1971;94:569-86.

4 Reid JD. Effects of flexion-extension movements of the head and spine upon the spinal cord and nerve roots. $J$ Neurol Neurosurg Psychiatry 1960;23:214-21.

${ }^{5}$ Adams CBT, Logue V. Studies in cervical spondylotic myelopathy. III. Some functional effects of operations for cervical spondylotic myelopathy. Brain 1971; 94:587-94.

${ }^{6}$ Gruninger W, Gruss P. The influence of the Cloward fusion operation on the motility of the cervical spine. In: Grote W, Brock M, Clar HE, Klinger M, Nau HE, eds. Advances in Neurosurgery, Vol. 8. Berlin:
Springer-Verlag, 1980:291-6.

${ }^{7}$ Gonsalez-Feria L, Peraita-Peraita P. Cervical Spondylotic Myelopathy: a cooperative study. Clin Neurol Neurosurg 1975;78:19-33.

* Taylor AR. Mechanism and treatment of spinal cord disorders associated with cervical spondylosis. Lancet 1953;I:717-20.

${ }^{9}$ Payne EE. The cervical spine and spondylosis. Neurochirurgia 1959;1:178-96.

"Taylor AR. Vascular factors in the myelopathy associated with cervical spondylosis. Neurology (Minneap) 1964:14:62-8.

"Adams CBT, Logue V. Studies on cervical spondylotic myelopathy. 1 . Movement of the cervical roots, dura and cord, and their relation to the course of the extrathecal roots. Brain 1971;94:557-68.

${ }^{12}$ Balla JI, Walton JN, Hankinson J. Cervical spondylosis (a follow-up study). Newcastle Med J 1964;28:191-203.

${ }_{13}^{3}$ Clarke E, Robinson PK. Cervical myelopathy: A complication of cervical spondylosis. Brain 1956;79:483-510.

${ }^{14}$ Campbell AMG, Phillips DG. Cervical disk lesions with neurological disorder. Br Med J 1960;2:481-5.

${ }^{15}$ Lees F. Aldren-Turner JW. Natural history and prognosis of cervical spondylosis. Br Med J 1963;2:1607-10.

${ }^{16}$ Roosen K, Grote W. Late results of operative treatment of cervical myelopathy. In: Grote W, Brock M, Clar $\mathrm{HE}$, Klinger M, Nau HE, eds. Advances in Neurosurgery, Vol. 8. Berlin: Springer-Verlag, 1980 69-77.

${ }^{17}$ Bradshaw P. Some aspects of cervical spondylosis. $Q J$ Med 1957;26:177-208.

${ }^{1 x}$ Nurick $\mathrm{S}$. The natural history and the results of surgical treatment of the spinal cord disorder associated with cervical spondylosis. Brain 1972;95:101-8. 